\title{
Hyperbaric Oxygen Therapy: Clinical Applications in Otorhinolaryngology
}

\author{
Joana Maria Soares Ferreira*1,2 ${ }^{*}$ Francisco Monteiro ${ }^{1}$, Joana Vilela Silva ${ }^{1}$, António Faria de Almeida ${ }^{1}$ and Artur \\ Condé $^{1}$ \\ ${ }^{1}$ Department of Otorhinolaryngology and Head and Neck Surgery, Centro Hospitalar Vila Nova de Gaia e Espinho E.P.E., Portugal
}

${ }^{2}$ PhD Student in Medicine and Molecular Oncology, Faculty of Medicine of University of Porto, Portugal

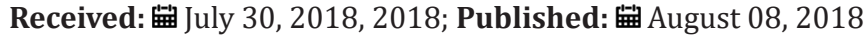

*Corresponding author: Joana Maria Soares Ferreira, Serviço de Otorrinolaringologia e Cirurgia de Cabeça e Pescoço do Centro Hospitalar de vila Nova de Gaia e Espinho E.P.E, Rua Conceição Fernandes 1079, 4434-502 Vila Nova de Gaia, Portugal

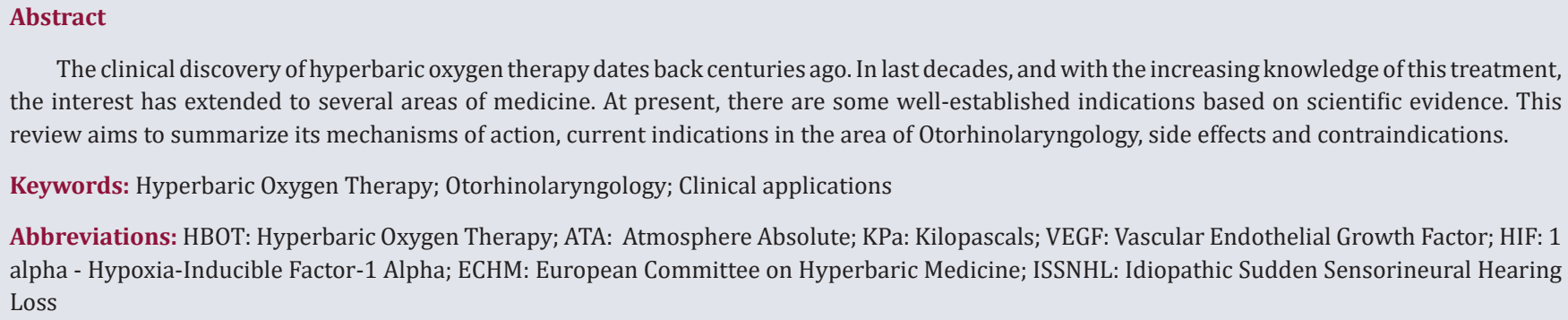

The clinical discovery of hyperbaric oxygen therapy dates back centuries ago. In last decades, and with the increasing knowledge of this treatment, the interest has extended to several areas of medicine. At present, there are some well-established indications based on scientific evidence. This review aims to summarize its mechanisms of action, current indications in the area of Otorhinolaryngology, side effects and contraindications.

Keywords: Hyperbaric Oxygen Therapy; Otorhinolaryngology; Clinical applications

Abbreviations: HBOT: Hyperbaric Oxygen Therapy; ATA: Atmosphere Absolute; KPa: Kilopascals; VEGF: Vascular Endothelial Growth Factor; HIF: 1 alpha - Hypoxia-Inducible Factor-1 Alpha; ECHM: European Committee on Hyperbaric Medicine; ISSNHL: Idiopathic Sudden Sensorineural Hearing Loss

\section{Introduction}

Hyperbaric Oxygen Therapy (HBOT) is defined as an intervention in which an individual breathes near $100 \%$ oxygen intermittently while inside a hyperbaric chamber that is pressurized to greater than sea level pressure [1 atmosphere absolute (ATA), which converts to 101.325 kilopascals (kPa)]. For clinical purposes, the pressure must equal or exceed 1.4 ATA (141.86 kPa) while breathing near $100 \%$ oxygen. By breathing $100 \%$ oxygen at high pressure, the oxygen dissolved in the plasma increases and consequently increases the oxygen that reaches the tissues.

The application of compressed gas in medicine had its origins three centuries ago. Over the time there have been advances and setbacks in the history of this form of treatment due to lack of scientific evidence. It was only in the last four decades that good science existed to support some of its current applications [1-2].

\section{Mechanisms of Action of HBOT}

One of the most interesting mechanisms induced by HBOT is angiogenesis mediated by the release of omnipotent stem cells, capable of differentiating into endothelial cells, and by the production of crucial mediators for the angiogenesis, such as vascular endothelial growth factor (VEGF) and hypoxia-inducible factor-1 alpha (HIF-1 alpha). In addition, hyperoxia-induced by
HBOT appears to improve microcirculation by increasing deformity of red blood cells and decreasing blood viscosity. Another welldescribed role of HBOT focuses on wound healing, where it seems to induce reactive oxygen species and reactive nitrogen species. Together these acts as signal transducers, promote growth factors, attenuate cell apoptosis and reduce inflammation. Importantly, HBOT also reduces wound infection by its direct effect on anaerobic bacteria, its indirect effect on aerobic bacteria by enhancing the microbicidal capability of polymorphonuclear leukocytes and acts synergically with antibiotics [3-8].

\section{Clinical Applications of HBOT in Otorhinolaryngology}

The current indications for HBOT were reviewed by European Committee on Hyperbaric Medicine (ECHM) in 2016. In otolaryngology, HBOT is strongly indicated as the primary method of treatment in the following situations: treatment of mandibular osteoradionecrosis, prevention of mandibular osteoradionecrosis after dental extraction, treatment of idiopathic sudden sensorineural hearing loss (ISSNHL), in all cases of compromised skin grafts and flaps (as soon as possible after the diagnosis of compromised grafts/tissues) and both pre- and postoperatively in cases where there is an increased risk for compromised skin grafts and flaps (e.g. irradiated or infected wound bed, immune- 
compromised patient). Experts also suggest HBOT in the treatment of osteoradionecrosis in other bones, soft tissue radionecrosis of the head and neck area, compromised skin grafts and in prevention or treatment of radio-induced lesions of the larynx, despite this last indication it is not yet supported by sufficiently strong evidence [9-10]. Recent studies have focused on its potential benefit in the minimization of post-radiation sequelae. [11-13] However, more controlled and randomized studies are needed to broaden the indications of this form of treatment.

\section{Adverse Effects}

HBOT is a relatively safe form of treatment with few and generally transient adverse effects. These complications can occur by two main mechanisms, due to the effect of the pressure on enclosed gas spaces or by the toxic effects of the oxygen. Ophthalmologic (eg. reversible myopia, worsening of the cataract) and otorhinolaryngologic complications (eg. barotrauma of the ear, sinus squeeze) may occur but are usually mild and transient. More serious, but also rarer, complications of HBOT include exacerbation of congestive heart failure, pulmonary edema, and retinal changes [14-16].

\section{Contraindications}

The only absolute contraindication is the untreated tension pneumothorax. However, there are several relative contraindications that should be recognized when considering treatment with oxygen hyperbaric therapy. These include febrile illness, convulsive disorder, hyperthyroidism, congestive heart failure, pulmonary diseases (eg. chronic obstructive pulmonary disease), pregnancy and claustrophobia [14-16].

\section{Conclusion}

Hyperbaric oxygen therapy is a long-established method of treatment that has been developed and adjusted to new scientific knowledge. The lack of serious side effects and relatively low cost makes it an excellent treatment option for various medical and surgical conditions. Following the principle of evidence-based medicine, more controlled and randomized studies are needed so that its indications can be extended to other types of clinical conditions.

\section{References}

1. Weaver KL (2014) Hyperbaric Oxygen Therapy Indications of The Hyperbaric Oxygen Therapy Indications Book (13th Edition). Best Publishing Company, Florida, pp. 9-11.

\section{ISSN: 2574-1241}

DOI: $10.26717 / B J S T R .2018 .07 .001543$

Joana Maria Soares Ferreira. Biomed J Sci \& Tech Res

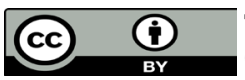

This work is licensed under Creative Commons Attribution 4.0 License

Submission Link: https://biomedres.us/submit-manuscript.php
2. Sharkey LS (2000) Current indications for hyperbaric oxygen therapy. ADF Health 1: 64-72.

3. Fosen KM, Thom SR (2014) Hyperbaric oxygen, vasculogenic stem cells, and wound healing. Antioxid Redox Signal 21: 1634-1647.

4. Hopf HW, Gibson JJ, Angeles AP, Constant JS, Feng JJ, et al. (2005) Hyperoxia and angiogenesis. Woud Repair Regen 13: 558-564.

5. Ztürk F, Ermertcan AT, İnanır I (2013) Hyperbaric oxygen therapy for the management of chronic wounds. Cutaneous and Ocular Toxicology 32(1): 72-77.

6. Sen CK, Khanna S, Gordillo G, Bagchi D, Bagchi M, et al. (2002) Oxygen, oxidants, and antioxidants in wound healing: an emerging paradigm. Annals of the New York Academy of Sciences 957: 239-249.

7. Godman CA, Chheda KP, Hightower LE, Perdrizet G, Shin DG, et al. (2010) Hyperbaric oxygen induces a cytoprotective and angiogenic response in human microvascular endothelial cells. Cell stress \& chaperones 15(4): 431-442.

8. Thom SR (2011) Hyperbaric oxygen: its mechanisms and efficacy. Plast Reconstr Surg 127 (Suppl 1): 131S-41S.

9. Mathieu D, Marroni A, Kot J (2017) Tenth European Consensus Conference on Hyperbaric Medicine: recommendations for accepted and non-accepted clinical indications and practice of hyperbaric oxygen treatment. Diving and Hyperbaric Medicine 47(1).

10. Singh S, Gambert SR (2014) Hyperbaric oxygen therapy: a brief history and review of its benefits and indications for the older adult patient. Ann Longterm Care 22 (7-8): 37-42.

11. Ravi P, Vaishnavi D, Gnanam A, Krishnakumar R V B (2017) The role of hyperbaric oxygen therapy in the prevention and management of radiation-induced complications of the head and neck- a systematic review of literature. J. Stomatol Oral Maxillofac Surg 118(6): 359-362.

12. Sultan A, Hanna GJ, Margalit DN, Chau N, Goguen LA, et al. (2017) The use of hyperbaric oxygen for the prevention and management of osteoradionecrosis of the jaw: A Dana-Farber/Brigham and Women's Cancer Center Multidisciplinary Guideline. The Oncologist 22: 343-350.

13. Raggio BS, Winters R (2018) Modern management of osteoradionecrosis. Curr Opin Otolaryngol Head Neck Surg. 26(4): 254-259.

14. Lam G, Fontaine R, Ross FL, Chiu ES (2017) Hyperbaric Oxygen Therapy: Exploring the Clinical Evidence. Adv Skin Wound Care 30(4): 181-190.

15. McMonnies CW (2015) Hyperbaric oxygen therapy and the possibility of ocular complications or contraindications. Clin Exp Optom 98(2): 122125.

16. Howell RS, Criscitelli T, Woods JS, Gillette BM, Gorenstein S (2018) Hyperbaric Oxygen Therapy: Indications, Contraindications, and Use at a Tertiary Care Center. AORN J 107(4): 442-453.

\section{https://biomedres.us/}

